\title{
Comparative study of pancreatic polypeptide (PP) secretion, endocrine and exocrine function, and structural damage in chronic alcohol induced pancreatitis (CAIP)
}

\author{
A S MEE, L J KLAFF, A H GIRDWOOD, M PAUL, \\ M TYLER, AND I N MARKS \\ From the Gastrointestinal Clinic and the Diabetes and Endocrine Research Group, Department of Medicine, \\ University of Cape Town and Groote Schuur Hospital, Observatory, Cape Town, South Africa
}

SUMMARY The serum pancreatic polypeptide response to intravenous Boots secretin (1.5 U/ $/ \mathrm{kg})$, glucose tolerance, and insulin responses have been studied in 25 patients with chronic alcohol induced pancreatitis of varying severity, and these results compared with a secretinpancreozymin test, and the structual damage noted on pancreatography. For the pancreatic polypeptide response 16 healthy subjects acted as controls. There was a marked reduction in pancreatic polypeptide response in patients with advanced structural changes of chronic alcohol induced pancreatitis compared with patients with minimal/moderate changes $(p<0.01)$ and with healthy controls $(\mathrm{p}<0.05)$ although there was no difference between the latter two groups. Similarly, while the ratio of peak to mean basal pancreatic polypeptide concentration was also significantly reduced in patients with advanced changes compared with healthy controls $(p<0.05)$ there was a marked degree of overlap in patients with lesser degrees of structural damage and control subjects. For all patients with chronic alcohol induced pancreatitis, however, there was a significant correlation between the pancreatic polypeptide response and each parameter of the standard secretin-pancreozymin test and with glucose tolerance and the integrated insulin response. We conclude therefore that while the secretin stimulated pancreatic polypeptide response correlates significantly with accepted tests of pancreatic structure and function, there is a significant degree of overlap in the response obtained in patients who have minimal/moderate damage and healthy controls making the test insufficiently sensitive for routine diagnostic use.

Human pancreatic polypeptide is produced by a pancreatic endocrine cell (PP cell) found in both the islets of Langherhans and scattered throughout the exocrine parenchyma. It is localised almost entirely to the panceas. ${ }^{1}$

Various workers have established that the release of pancreatic polypeptide in response to a variety of stimuli is reduced in patients with gross chronic pancreatitis and overt exocrine insufficiency. The stimuli which have been used include insulin hypoglycaemia where the effect is mediated via the vagus $^{2}$ and a test meal $^{34}$ or meat extract ${ }^{5}$ where

\footnotetext{
Address for correspondence: Dr A S Mee, Department of Gastroenterology, Central Middlesex Hospital, Acton Lane, London, NW10 7NS.

Received for publication 18 October 1982
}

pancreatic polypeptide release is elicited via an entero-PP axis which is partly humoral and partly vagally controlled.

Secretin is also a potent stimulus of pancreatic polypeptide release $^{6}{ }^{5}$ and bypasses the entero-PP axis to act directly on the pancreas. Studies in which secretin has been used as the stimulant of pancreatic polypeptide release, however, have usually only been done in a small group of patients with chronic pancreatitis and overt exocrine deficiency in whom structural changes were not reported ${ }^{2} 8$ or in a larger group where patients had been diagnosed as having chronic pancreatitis on the basis of gross structural change, calcification or exocrine insufficiency ${ }^{9}$ - that is, patients with advanced disease although more recently the same group have 
reported similar results in patients with lesser degrees of pancreatic damage. ${ }^{10} \mathrm{We}$ have therefore systematically studied a group of patients with a clinical diagnosis of chronic alcohol induced pancreatitis by means of secretin-stimulated human pancreatic polypeptide release, a secretinpancreozymin test, glucose tolerance test with insulin response, and endoscopic retrograde cholangio-pancreatography (ERCP) in order to assess the value of secretin stimulated human pancreatic polypeptide release as a test of pancreatic function and to compare this with the structural changes noted on pancreatography.

\section{Methods}

\section{PATIENTS}

Twenty five patients known or suspected to have chronic alcohol induced pancreatitis were studied as part of their routine pancreatic assessment. There were 23 men and two women, mean age 44 years (range 27-58 years). Patients with an episode of acute pancreatitis in the previous eight weeks, or a pancreatic cyst were excluded as were insulin dependent patients with pancreatic polypeptide antibodies. ${ }^{11}$ No patient had biochemical evidence of alcoholic liver disease. All patients were screened for evidence of autonomic neuropathy using methods previously described. ${ }^{12}$ The control group for secretin stimulated pancreatic polypeptide secretion comprised 16 healthy subjects from the hospital staff. There were 13 men and three women, mean age 35 years (range $20-53$ years).

\section{TEST PROCEDURE}

All tests of pancreatic polypeptide release were done at 8 am after an overnight fast. With the subject comfortably seated a heparinised intravenous cannula was inserted into an antecubital vein and blood taken 15 minutes and immediately before giving an injection of Boots secretin (batch No. $91510 / 4$, pancreatic polypeptide content $3.8 \mathrm{ng} /$ unit) $1.5 \mathrm{U} / \mathrm{kg}$ body weight over two minutes into the opposite antecubital vein. Blood samples were then taken at two, five, 10, 15, and 30 minute intervals after the secretin injection, allowed to clot, separated by centrifugation and the serum stored at $-20^{\circ} \mathrm{C}$ until assayed.

Glucose tolerance tests were also performed at 8 am after an overnight fast in all non-insulin dependent patients. After insertion of a heparinised intravenous cannula into an antecubital vein a baseline blood sample for glucose and insulin was obtained after which patients swallowed $75 \mathrm{~g}$ glucose dissolved in $200 \mathrm{ml}$ water. Further blood samples were taken at $30,60,90$, and 120 minutes.
Glucose tolerance tests were classified as normal impaired or diabetic according to the criteria of the National Diabetes Data Group. ${ }^{13}$

Pancreatic exocrine function was tested using the method described by Bank et al. ${ }^{14}$ Briefly, duodenal juices were collected at 10 minute intervals for $\mathbf{6 0}$ minutes after an intravenous bolus of Boots secretin $(1.5 \mathrm{U} / \mathrm{kg})$ and for a further 20 minutes after an intravenous bolus of Boots pancreozymin $(1 \mathrm{U} / \mathrm{kg})$. The duodenal contents were then analysed for volume, bicarbonate, amylase, trypsin, chymotrypsin, and lipase concentrations.

Endoscopic retrograde cholangio-pancreatography was performed in the standard manner ${ }^{15}$ and the pancreatograms assessed blindly by three independent observers according to Kasugai's classification. ${ }^{16}$

\section{LABORATORY METHODS}

Serum was assayed for pancreatic polypeptide by methods previously described. ${ }^{2}$ Rabbit human pancreatic polypeptide antiserum, pancreatic polypeptide for standards and bovine pancreatic polypeptide for iodination as tracer were kind gifts from Dr R E Chance, Lilly Research Laboratories, Indianapolis, Indiana. All serum samples were assayed as a single batch. Serum insulin was measured using a radioimmunoassay kit purchased from CEA Sorin (France). Blood glucose was measured by the neocuprine method using a Technicon autoanalyser.

\section{STATISTICAL METHODS}

The integrated glucose, integrated insulin, and integrated pancreatic polypeptide responses were calculated from the formula of Richardson et $a^{17}$ and measured as the rise in pancreatic polypeptide over the 15 minute time period. Results were expressed as $\mathrm{pmol} / \mathrm{min} / \mathrm{l}$. Correlation coefficients were calculated using the Rank Spearman test and significant differences between groups by the Mann Whitney U test.

\section{Results}

ERCP GRADING

Five patients were classified as having minimal, five as moderate, and 15 as advanced chronic pancreatitis on the basis of the structural changes noted on pancreatography. The endoscopic retrograde cholangio-pancreatography grading thus provided a measure of the severity of the disease.

STEATORRHOEA

One patient with moderate and six patients with advanced disease had biochemical steatorrhoea 
(faecal fat excretion $>19 \mathrm{mmol} / \mathrm{d}$ ). This was clinically overt in the one patient with moderate changes and in four of the patients with severe changes.

\section{GLUCOSE TOLERANCE TESTS}

Glucose tolerance was normal in the four patients with minimal pancreatitis who underwent the test. Of the four patients in the moderate group who had a glucose tolerance test there were two normal, one impaired, and one diabetic glucose tolerance curves. Of the 15 patients with advanced pancreatitis, eight were known diabetics, while five had impaired glucose tolerance and two a normal result. The mean integrated glucose responses $( \pm$ SEM) were: minimal pancreatitis $713 \pm 117 \mathrm{mmol} / \mathrm{min} / \mathrm{l}$; moderate pancreatitis $1282 \pm 448 \mathrm{mmol} / \mathrm{min} / \mathrm{l}$; advanced pancreatitis $1472 \pm 164 \mathrm{mmol} / \mathrm{min} / \mathrm{l}$. There was a significanit negative correlation between the integrated glucose response and the pancreatic polypeptide response $(\mathrm{r}=-0.54 ; \mathrm{p}<0.01)$.

\section{INTEGRATED INSULIN RESPONSE}

The mean integrated insulin response ( \pm SEM) values were: minimal pancreatitis $6915 \pm 1479 \mathrm{mU} /$ $\mathrm{min} / \mathrm{l}$; moderate pancreatitis $7181 \pm 2581 \mathrm{mU} / \mathrm{min} /$; advanced pancreatitis $4236 \pm 1243 \mathrm{mU} / \mathrm{min} / \mathrm{l}$. The integrated insulin response correlated significantly with the integrated pancreatic polypeptide response $(r=0.74 ; p<0.001)$, with the endoscopic retrograde cholangio-pancreatography score $(r=0.46, p<0.05)$, and the secretin-pancreozymin test score $(r=0.58$, $\mathrm{p}<0 \cdot 01)$.

\section{PANCREATIC POLYPEPTIDE RESPONSE}

As the pancreatic polypeptide response to secretin was not significantly different between patients with minimal and moderate pancreatitis these two groups were combined. The combined group did not differ significantly from the healthy control group (Fig. 1). There was, however, a marked reduction in the peak pancreatic polypeptide response between patients with severe structural changes and both the healthy controls and the combined minimal/ moderate pancreatitis group. (Severe chronic alcohol induced pancreatitis $v s$ healthy controls $\mathrm{p}<0.05$; severe chronic alcohol induced pancreatitis vs $\mathrm{min} / \mathrm{mod}$ chronic alcohol induced pancreatitis $p<0.01$.) The differences in the integrated pancreatic polypeptide response between groups on the basis of their endoscopic retrograde cholangiopancreatography grading is shown in Fig. 2.

SECRETIN-PANCREOZYMIN TEST (STANDARD PFT) The pancreatic polypeptide response to secretin correlated significantly with all parameters of the

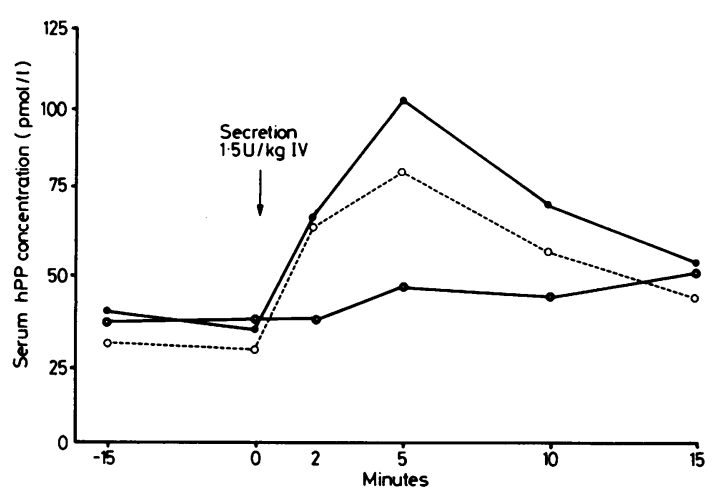

Fig. 1 Mean serum pancreatic polypeptide $(P P)$ response to $1.5 \mathrm{U} / \mathrm{kg}$ intravenous Boots secretin in 16 healthy control subjects (0...-. ), 10 patients with minimal/moderate

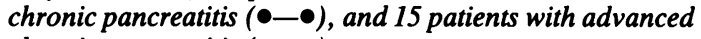
chronic pancreatitis (O-০).

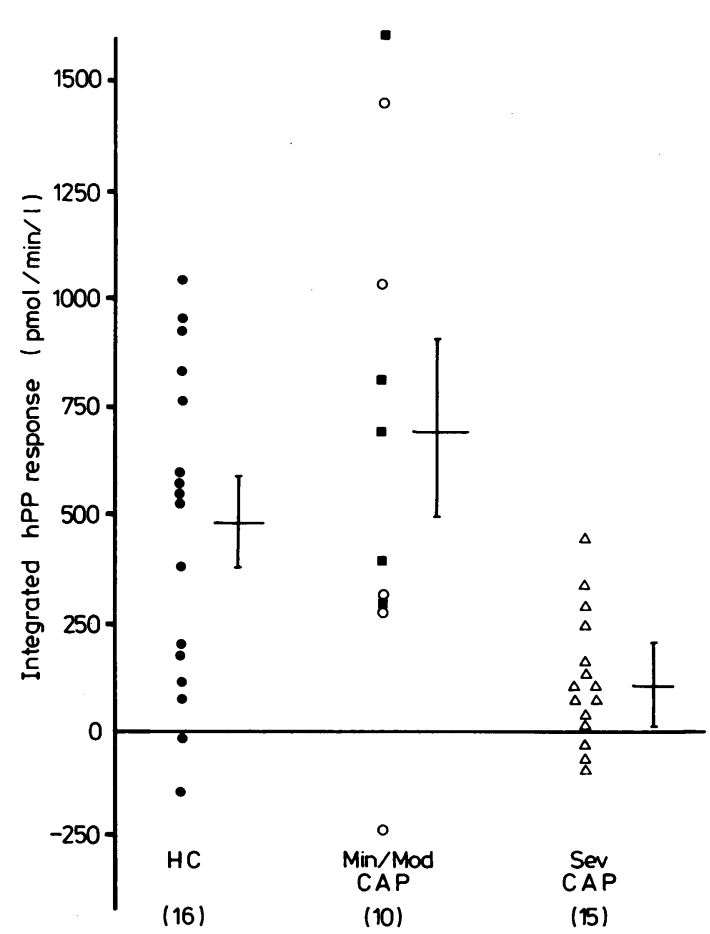

Fig. 2 Integrated pancreatic polypeptide $(P P)$ response to $1.5 \mathrm{U} / \mathrm{kg}$ intravenous Boots secretin in 16 healthy control subjects $(\bullet)$, six patients with minimal $(\circ)$, five patients with moderate (घ), and 15 patients with advanced chronic pancreatitis $(\Delta)$. 
standard PFT (Table). The best correlation was seen with volume, mean bicarbonate, trypsin, and lipase concentrations.

PEAK/BASAL PANCREATIC POLYPEPTIDE RATIO The ratios of peak to mean basal pancreatic polypeptide level (mean \pm SD) were: healthy controls $2 \cdot 7 \pm 1 \cdot 6$; minimal pancreatitis $3 \cdot 2 \pm 1 \cdot 3$; moderate pancreatitis $2 \cdot 5 \pm 1 \cdot 4$; and advanced pancreatitis $1 \cdot 7 \pm 0 \cdot 6$. There was a significant difference in the ratio between healthy controls and patients with advanced pancreatitis $(<0.05)$.

\section{Discussion}

The diagnosis of advanced chronic pancreatitis, as opposed to lesser degrees of pancreatic damage, is not usually difficult. A variety of tests of pancreatic function are available to corroborate a suggestive clinical history. ${ }^{18}$ These include methods of determining exocrine or endocrine insuffiency - for example, three day faecal fat collections, Lundh meal, secretin-pancreozymin test, glucose tolerance test - although all suffer from either a lack of sensitivity or specificity or are invasive and technically difficult to perform. A recent test of pancreatic function, the Bz-Ty PABA test ${ }^{19}$ is easy to perform and therefore attractive but also not without problems of sensitivity compared with standard tests of pancreatic exocrine function in patients with less severe disease. ${ }^{20}$

Despite its drawbacks it would appear, therefore, that the secretin-pancreozymin test remains the standard method of detecting pancreatic exocrine damage and the one with which other more recent tests should be compared. ${ }^{18}$

Endoscopic retrograde pancreatography gives direct information about the major pancreatic duct systems and frequently shows morphological changes of minimal or moderate chronic pancreatitis which correlate with other parameters of pancreatic function. ${ }^{16}$ While of great value in establishing a

Table Correlation of integrated PP response (IPRF) with standard PFT values

\begin{tabular}{lll}
\hline & $r$ & $p$ \\
\hline $\begin{array}{l}\text { Integrated PP response } v s \\
\text { Volume }\end{array}$ & 0.72 & $<0.001$ \\
Max bicarb & 0.5 & $<0.01$ \\
Mean bicarb & 0.7 & $<0.001$ \\
Amylase & 0.61 & $<0.001$ \\
Trypsin & 0.7 & $<0.001$ \\
Chymotrypsin & 0.64 & $<0.001$ \\
Lipase & 0.7 & $<0.001$ \\
PFT score & 0.7 & $<0.001$ \\
\hline
\end{tabular}

diagnosis of chronic pancreatitis, however, the pancreatogram may occasionally be misleading and observer variation can occur. ${ }^{21}$

There remains, therefore, no simple reliable test of pancreatic function especially for patients with lesser degrees of pancreatic damage who may nevertheless have severe symptoms. Reports on the use of serum pancreatic polypeptide concentrations obtained in response to either a meal or secretin stimulus have ranged from the enthusiastic, ${ }^{5810}$ to the cautious, ${ }^{3}{ }^{4}$ possibly reflecting different degrees of pancreatic damage in the various patient groups.

The present study systematically investigates human pancreatic polypeptide secretion in patients with varying degrees of pancreatic damage and, compares the results obtained with currently accepted 'best' tests of pancreatic structure and function. We have shown, therefore, that for patients with severe structural changes of chronic pancreatitis there is a good correlation between the extent of damage, functional impairment, and pancreatic polypeptide secretion. For all stages of chronic pancreatitis there is a good correlation between the pancreatic polypeptide response and the endoscopic retrograde cholangio-pancreatography, secretin-pancreozymin test, glucose tolerance tests, and integrated insulin response. This agrees with the findings of Owyang et al ${ }^{2}$ who used cholecystokinin octapeptide to stimulate pancreatic polypeptide secretion. The results of the glucose tolerance tests and integrated insulin response need to be interpreted with caution as in the majority of patients this test was performed two days after the endoscopic retrograde pancreatogram, and a recent study has suggested that glucose tolerance remains impaired for up to six weeks after pancreatography. ${ }^{23}$ Nevertheless, other authors have shown a correlation between insulin responses and exocrine function $^{24}$ and these observations have now been extended in the present study to show a similar correlation with structural damage.

Nyboe Andersen et $a l^{25}$ have recently reported that $C$ peptide responses to glucose and glucagon correlated with exocrine pancreatic function in patients with chronic pancreatitis while Frier et a ${ }^{26}$ found a similar correlation in non-pancreatitics with type I diabetes. These workers have suggested that the abnormalities in pancreatic function are related to insulin deficiency although our observations clearly show that insulin deficiency in chronic pancreatitis correlates with the degree of exocrine pancreatic destruction, a process which does not occur in type I diabetes.

Although there was a signiticant correlation between pancreatic polypeptide response and structural changes of chronic pancreatitis the 
pancreatic polypeptide test cannot be relied on as a test of pancreatic function. Some healthy controls may have an impaired response (Fig. 2) while some patients with even advanced structural damage can have responses within the normal range. Neither does the present study support the findings of Stern et al $^{10}$ who also used Boots secretin. They suggested that a peak/basal ratio of less than five differentiated $90 \%$ of patients with chronic pancreatitis from their control group. In the present study only one of the healthy control group in fact achieved a ratio of greater than five and even between healthy controls and patients with severe disease there was a degree of overlap. It is unlikely that a slightly increased dose of secretin (2 U/kg vs $1.5 \mathrm{U} / \mathrm{kg})$ accounted for this difference as Glaser $e t a l^{7}$ found no difference in response between the two dosages although differences in the batches of secretin used is a possibility. The difference in ratio appears to be due primarily to lower basal pancreatic polypeptide values in the Australian study, the reason for which is not known, although the authors' endoscopic retrograde cholangio-pancreatography criteria for moderate pancreatitis includes a strictured main duct a feature which from the classification system used suggests more advanced changes. ${ }^{16}$

The pancreatic polypeptide response in patients with minimal or moderate structural changes and in general preserved exocrine and endocrine function is significantly different from patients with advanced changes. Alterations in cholinergic control or vagal tone are a possible cause for this difference. An alternative explanation, however, is offered by a recent study which found that meal stimulated pancreatic polypeptide release was significantly greater in otherwise healthy alcoholics than in controls. ${ }^{27}$ It is possible therefore that chronic alcohol abuse enhances the pancreatic polypeptide response until pancreatic damage becomes severe enough to impair pancreatic polypeptide production.

We conclude, therefore, that while pancreatic polypeptide secretion in response to intravenous Boots secretin is a simple, non-invasive procedure which correlated significantly with accepted tests of pancreatic structure, exocrine, and endocrine function, the degree of overlap between healthy controls and patients with chronic pancreatitis makes the test unsuitable for routine diagnostic use.

We are grateful to the South African Medical Research Council and to the University of Cape Town Staff Research funds, and the National Cancer Association of South Africa for financial assistance.

\section{References}

1 Larsson LI, Sundler F, Håkanson R. Immunohistochemical localization of human pancreatic polypeptide (hPP) to a population of islet cells. Cell Tissue Res 1975; 156: 167-71.

2 Sive A, Vinik AI, van Tonder S, Lund A. Impaired pancreatic polypeptide secretion in chronic pancreatitis. J Clin Endocrinol Metab 1978; 47: 556-9.

3 Andersen BN, Hagen V, Klein HC, Stadil F, Worning $H$. Correlation between exocrine pancreatic secretion and serum concentration of human pancreatic polypeptide in chronic pancreatitis. Scand J Gastroenterol 1980; 15: 699-704.

4 Valenzuela JE, Taylor IL, Walsh JH. Pancreatic polypeptide response in patients with chronic pancreatitis. Dig Dis Sci 1979; 24: 862-4.

5 Yamamura T, Mori $\mathrm{K}$, Tatsumi M, Kotoura $\mathrm{Y}$, Yoshiya K, Itoh N, Seino Y. Availability of plasma pancreatic polypeptide measurement in diagnosis of chronic pancreatitis. Scand J Gastroenterol 1981; 16: 757-61.

6 Adrian TE, Bloom SR, Besterman HS, Barnes AJ, Cooke TJC, Russell RCG, Faber RG. Mechanisms of pancreatic polypeptide release in man. Lancet 1977; 1: 161-3.

7 Glaser B, Vinik AI, Sive AA, Floyd JC. Plasma human pancreatic polypeptide - responses to administered secretin: effects of surgical vagotomy, cholinergic blockade and chronic pancreatitis. J Clin Endocrinol Metab 1980; 50: 1094-9.

8 Adrian TE, Besterman HS, Mallinson CN, Garalotis C, Bloom SR. Impaired pancreatic polypeptide release in chronic pancreatitis with steatorrhoea. Gut 1979; 20: 98-101.

9 Stern AI, Hansky J. Secretin stimulated pancreatic polypeptide: a test for chronic pancreatitis. Aust $N Z \mathrm{~J}$ Med 1981; 11: 351-4.

10 Stern I, Roberts-Thomson IC, Hansky J. Correlation between pancreatic polypeptide response to secretin and ERCP findings in chronic pancreatitis. Gut 1982; 23: 235-8.

11 Klaff LJ, Vinik AI, Berelowitz M, Jackson WPU. Circulating antibodies in diabetes treated with monocomponent and conventional insulin. South Afr Med J 1978; 54: 149-53.

12 Levitt NS, Vinik AI, Sive AA, Child PT, Jackson WPU. Studies on plasma glucagon concentration in maturity onset diabetes with autonomic neuropathy. Diabetes 1979; 28: 1015-21.

13 National Diabetes Data Group. Classification and diagnosis of diabetes mellitus and other categories of glucose intolerance. Diabetes 1979; 48: 1039-57.

14 Bank S, Marks IN, Moshal MG, Efron G, Silber W. The pancreatic-function test: method and normal values. South Afr Med J 1963; 37: 1061-6.

15 Cotton PB. Progress report - ERCP. Gut 1977; 18: 316-41.

16 Kasugai T, Kuno N, Kizu M, Kobayashi S, Hattori K. Endoscopic pancreatocholangiography II. The pathological endoscopic pancreatocholangiogram. Gastroenterology 1972; 63: 227-34. 
17 Richardson CT, Walsh JH, Hicks MI, Fordtran JS. Studies on the mechanisms of food stimulated gastric acid secretion in normal human subjects. $J$ Clin Invest 1976; 58: 623-31.

18 Arvanitakis C, Cooke AR. Diagnostic tests of exocrine pancreatic function and disease. Gastroenterology 1978; 74: 932-48.

19 Mitchell C, Humphrey CS, Bullen AW, Kelleher J. Diagnostic value of an oral pancreatic function test. Scand J Gastroenterol 1979; 14: 183-7.

20 Hoek FJ, Sanders GTB, Teunen A, Tijtgat GNJ. In vitro and in vivo analysis of the PABA test compared with the Lundh test - influence of intraluminal $\mathrm{pH}$. Gut 1981; 22: 8-13.

21 Reuben A, Johnson AL, Cotton PB. Is pancreatogram interpretation reliable? - a study of observer variation and error. Br J Radiol 1978; 51: 956-62.

22 Owyang C, Scarpello JH, Vinik AI. Correlation between pancreatic enzyme secretion and plasma concentration of human pancreatic polypeptide in health and in chronic pancreatitis. Gastroenterology
1982; 83: 55-62.

23 Tulassay Z, Papp J, Szathmári M, Kisfaludy S, Korányi L, Támas G. Changes in glucose tolerance after endoscopic retrograde cholangio pancreatography. Gut 1981; 22: 575-8.

24 Kalk WJ, Vinik AI, Jackson WPU, Bank S. Insulin secretion and pancreatic exocrine function in patients with chronic pancreatitis. Diabetologia 1979; 16: 355-8.

25 Nyboe Andersen B, Krarup T, Thorsgaard Pedersen $\mathrm{N}$, Faber $\mathrm{OK}$, Hagen $\mathrm{C}$, Worning $\mathrm{H}$. B cell function in patients with chronic pancreatitis and its relation to exocrine pancreatic function. Diabetologia 1982; 23: 86-9.

26 Frier B, Faber OK, Binder C, Elliott HL. The effect of residual insulin secretion on exocrine pancreatic function in juvenile-onset diabetes mellitus. Diabetologia 1978; 14: 301-4.

27 Fink RS, Adrian TE, Margot D, Bloom SR. Increased pancreatic polypeptide in chronic alcohol abuse. (Abstract.) Gut 1981; 22: A863. 